\title{
LA SITUACIÓN DE LA MUJER EN EL LIBRO DE TOBÍAS
}

\section{Introducción}

El presente artículo utiliza el acercamiento de la antropología cultural, centrado en el papel que juega la mujer en el libro de Tobías, con una doble finalidad. Además de esclarecer cuál era el rol cultural de la mujer, quiere ayudar a situar el lugar de composición, pues ninguna propuesta al respecto ha sido definitiva.

Inicia presentando a las familias que forman parte de la narración, posteriormente analiza las relaciones de las mujeres. Finalmente indaga sobre la situación de la mujer en algunos libros de la época, escritos en Egipto y en Palestina, para concluir que seguramente Tobías no fue escrito en esa zona.

\section{Las familias}

En el libro de Tobías se trata, básicamente, de tres familias. ${ }^{1}$ La primera, formada por Tobit, Ana y Tobías; la segunda, por Ragüel, Edna

${ }^{1}$ Si la situación de las familias judías en las épocas helenística y romana ha sido poco estudiada, más precario es aún nuestro conocimiento de ellas en Mesopotamia y Persia durante el mismo período. 
y Sara; y la tercera, por Tobías y Sara. Lo primero que llama la atención es que se trata de tres familias presentadas como modelos de cumplimiento de la Ley y que las tres son monogámicas y estables, a pesar de que la ley permitió siempre que los varones tuvieran varias esposas y el divorcio. $^{2}$ Los libros sapienciales son testimonio de que el ideal monogámico y el rechazo del divorcio se fueron haciendo comunes en el Israel precristiano. El profeta Malaquías se atrevió a afirmar, en contradicción con la ley, que Dios repudiaba el divorcio (cf. 2,14-16). Nos encontramos, pues, con unas familias que se corresponden con un ideal postexílico, y en cierta disonancia con las normas legales vigentes.

Quien llevaba las riendas de las tres familias era el padre. ${ }^{3}$ Era él quien tomaba las decisiones. Tobit, por ejemplo, decidió enviar a su hijo Tobías, presuntamente un muchacho de entre doce y trece años, a un viaje peligroso, sin consultarlo con su esposa Ana, quien después manifestó su oposición. Ragüel entregó a su hija Sara a Tobías, aunque era una obligación ante la ley, sin siquiera comentar algo a su esposa Edna. Tobías exigió que Sara le fuera entregada como esposa sin saber su opinión. Es claro que, en este sentido, el libro representa la cultura de la época.

Según la ley, sólo los varones heredaban los bienes de sus padres. ${ }^{4}$ El primogénito recibía el doble que los demás hermanos. ${ }^{5}$ Las mujeres no

${ }^{2}$ Cf. Dt 24,1-4. Y esto es más importante por el hecho de que el libro de Tobías es marcadamente deuteronomista. Cf. J. Coluıns, "Marriage, Divorce, and Family in Second Temple Judaism", Families in Ancient Israel (ed. Perdue et al.), The Family, Religion and Culture, Westminster John Knox Presss - Luisville - 1997, 105, dice: "Desafortunadamente, no tenemos virtualmente ninguna evidencia acerca de la vida familiar en las aldeas rurales en el período del segundo templo". Por su parte, R. KRAMER, "Jewish Mothers and Daughters in the Greco-Roman World", The Jewish Family in Antiquity (ed. C. Shaye), Brown Judaic Studies 289, Scholars Press - Atlanta - 1993, 89112 , constata que se ha puesto poca atención, en los estudios científicos, en las relaciones familiares de los judíos de la antigüedad (época greco-romana). Es preciso tener en cuenta que el estudio de la situación de la mujer judía en el período helenista y en el principio del período romano, tiene limitaciones muy serias, debido a la naturaleza de los escritos que poseemos de aquella época. Una breve recapitulación de dicha problemática se encuentra en el prefacio de A.-J. LEVINE, Women Like This. New Perspectives on Jewish Women in the Greco-Roman World (ed. A.-J. Levine), JBL Early Judaism and its Literature 1, Scholars Press - Atlanta - 1991, XI-XVII.

3 Él era quien debía enseñar la ley a sus hijos. Notemos, sin embargo, que en su ausencia lo podía hacer una mujer, como en el caso de Tobit y Débora (cf. Tb 1,8).

${ }^{4}$ Cf. Nm 27,8.

${ }^{5}$ Cf. Dt 21,17 . 
heredaban, salvo si no tenían hermanos. En ese caso, debían casarse con un miembro de la familia, para que los bienes no quedaran enajenados. ${ }^{6}$

Las familias, según parece, eran extendidas, es decir, formadas por más de dos generaciones, y viviendo juntos los hermanos con sus respectivas esposas. ${ }^{7}$ Tobías y Sara vivieron con los padres de Tobías, en Nínive, hasta que ellos murieron; luego fueron a vivir con los padres de Sara, también hasta que murieron. En la práctica, la familia de Tobit era nuclear, puesto que él y Ana y sólo habían tenido un hijo: Tobías. Lo mismo que la familia de Ragüel y Edna, cuya única hija fue Sara. La narración permite pensar que ambas parejas habrían tenido otros hijos, pero que ellos habrían muerto en su primera infancia, pues la mortalidad infantil, como dije antes, era muy alta.

El libro de Tobías insiste en el amor entre padres e hijos: Tobit y Ana amaban a Tobías, él era la luz de sus ojos. Por su parte, Tobías amaba a sus padres, no les falló, siguió sus enseñanzas y los sepultó con honores. Lo mismo puede decirse de Ragüel y Edna. Ellos amaban a Sara, pues les costó mucho desprenderse de ella una vez que se había casado. Sara amaba a su padre, ${ }^{8}$ al grado que decidió, por ese amor, no suicidarse. Su relación con Edna era más estrecha, ambas lloraron juntas por la desgracia de Tobit, y de nuevo lloraron cuando Edna la llevó a la habitación en la que esperaría la llegada de su esposo Tobías (cf. Tb 7,1415). En esa ocasión, Edna le dirigió unas palabras de consuelo y de esperanza. ${ }^{9}$ Tobit llama repetidamente "hija" a Sara (cf. 11,17), con lo que se recalca el ambiente familiar en el que vivirá, pero también la situación de sumisión en la que iba a permanecer en su casa.

Tal vez Sara tenía a su cargo la dirección de las criadas (cf. 3,8), y es posible que eso constituyera su única responsabilidad en la casa de su padre. No tenía necesidad de trabajar ni de salir de su casa. Tobías

${ }_{7}^{6} \mathrm{Cf} . \mathrm{Nm} \mathrm{36,8.}$

7 Sin embargo, es muy probable que, debido a la alta mortalidad, sobre todo de niños, las familias no tuvieran normalmente, más de una o dos generaciones y cuatro o cinco componentes. Cf. A. Tropper, "Children and Childhood in Light of the Demographic of the Jewish Family in Late Antiquity", JSJ 37 (2006) 294-343 (esp. 338), que, aunque se refiere a las familias judías del período romano, puede dar una idea bastante clara de la situación de las familias en la época helenística.

${ }^{8}$ En su oración (cf. 3,10), Sara habla de la reputación su padre, no de Edna.

${ }^{9}$ Es muy probable que la madre fuera la encargada de preparar a las hijas para el matrimonio, como dice la Asunción de Moisés (latín), 11,12; se volverá sobre esto más adelante. 
tampoco aportaba dinero a la economía familiar, pero su situación era muy diferente. Su familia vivía precariamente y su madre tenía que mantener a los dos varones. Otra razón por la que él no sostenía a la familia, podría ser que aún no alcanzaba la edad suficiente. No se habla de que asistiera a alguna escuela y seguramente su fuente de educación eran sus padres.

\section{Amor y sexo}

El tema del amor es muy sugestivo. La palabra se usa sólo dos veces. La primera referida al demonio Asmodeo, de quien se dice que amaba a Sara. El texto es Tb 6,15:

Ahora yo temo a ese demonio que la ama, ${ }^{10}$ porque no le hace daño a ella, pero si alguien se le quiere acercar lo mata. Yo soy el unigénito de mi padre; no sea que muera y por culpa mía haga bajar con tristeza a mi padre y a mi madre a su sepulcro. Ellos no tienen otro hijo para que los sepulte.

El amor de Asmodeo por Sara era estéril y podría representar la esterilidad que, para la comunidad en la diáspora, significaba el matrimonio exogámico. ${ }^{11}$

El otro texto es 6,19 , está justo después de que Rafael explicó a Tobías que Sara era prudente, hija única, que era su pariente y que él la

10 "Temo a ese demonio que la ama", según 4Q196 (4QTob arª). 4QTob196-199 son cuatro grupos de fragmentos encontrados en Qumrán. 4Q200 (4QTob hebr) es un grupo de fragmentos en hebreo. La nomenclatura es usada por J. FITZMYER, Qumran Cave 4. XIV Parabiblical texts, part 2 (ed. M. Broshi et al.), DJD XIX, Clarendon Press Oxford - 1995. Los códices A y B (Alejandrino y Vaticano), dicen: "temo morir, como los primeros, pues un demonio la ama". La Siro-Hexaplar dice: "temo no regresar y morir como los primeros, pues un demonio la ama". También la Vetus Latina MPQ (M: Monacensis, 130, Munich; P: Sangermanensis, 150 París; Q: Regius, 148, París) y los minúsculos 44, 106 y 107 dicen que el demonio amaba a Sara. S (Sinaítico) dice: "[...] temo, pues a ella $[\ldots]^{\prime \prime}$.

11 El demonio puede ser entendido, también, como el seductor paradisíaco de Eva, que no había obtenido el consentimiento de Sara. La seducción de Eva por el demonio se convirtió en una tradición judía muy recordada. Como ejemplo de ello están 2 Henoc, Apocalipsis de Abraham, y la Vida de Adán y Eva. Cf. G. FASSBECK, "Tobit's Religious Universe between Kinship Loyalty and the Law of Moses", JSJ 37 (2005) 173-196. La oración de Tobías y Sara, antes de acostarse, alude a uno de los relatos de la creación. Ese podría ser un recurso para hacer pensar al lector que, a partir de la pareja Tobías-Sara, se iniciaba una nueva creación, en la que la mujer no era seducida. La relación de Sara con Eva es significativa. Sin embargo, Sara nunca parece ser consciente de que un demonio la ama y que por ello mata a sus maridos. 
podía "curar" del demonio que mataba a sus maridos. Dice: "Cuando Tobías escuchó las palabras de Rafael y que era su hermana, del linaje de la casa de su padre, ${ }^{12}$ se enamoró mucho de ella y se apegó su corazón a ella". ${ }^{13}$ Es evidente que no se trata de un enamoramiento de Sara, en el sentido romántico que ahora privilegiamos, sino sólo de lo ventajoso del matrimonio. Para Tobías todo se ensamblaba perfectamente. Era una invitación clara de Dios. Aquel matrimonio era lo que tenía que hacer.

De cualquier forma, está claro que Tobías no se casó con Sara porque la amara -en el sentido en que entendemos el término hoy en día-. Sin embargo, si ponemos atención a la situación de Sara, la realidad es todavía más cruda. Ella había sido entregada en matrimonio a siete varones. No se puede presumir que amara ni siquiera al primero, pues los padres hacían los arreglos de las bodas. Pero podríamos pensar que tenía ilusión de casarse. Es posible que todavía tuviera ilusión cuando se trataba del segundo. Pero el texto muestra claramente que, después de siete bodas, ni ella ni sus padres deseaban otro matrimonio. Sara, además, se enteró de la boda unos minutos antes de que se realizara (cf. 7,7). Ella no estaba en la mesa cuando su padre y Tobías hicieron los arreglos. Una vez que Tobías insistió en que Sara debía entregársele, Ragüel la llamó para entregarla a su nuevo esposo (cf. 7,12). Cuando se terminó la ceremonia del acta de matrimonio, Sara fue llevada al aposento al que llegaría luego Tobías, su esposo, para mantener la primera relación sexual, un hombre al que había visto dos veces, esa misma tarde.

Por otro lado, como dije antes, me parece suficientemente claro en el texto, que Tobías era un muchacho, tal vez de entre doce y trece años. Creo esto, porque Tobit lo trata como a un niño hasta el momento del envío. Tobit dependía del trabajo de su esposa Ana, lo cual significa que Tobías no aportaba dinero a la casa. Rafael, de hecho debería ser su tutor

12 B A, la Siro-Hexaplar, el Arameo (A. NeuBAuer, The Book of Tobit. The Text in Aramaic, Hebrew, and Old Latin with English Translations, Eugene Oregon: Wipf \& Stock, 2005²) y Fagius (Políglota de Walton, como está en Apocrypha [ed. R. H. Charles], Clarendon Press - Oxford - 1963) omiten: "las palabras de Rafael y que era su hermana, del linaje de la casa de su padre", y en su lugar ponen sólo: "esto".

13 El arameo omite: "y se apegó su corazón a ella". Esta omisión también se da en la Vulgata. De ello hablamos más adelante. Fagius añade: "antes de verla". Varios testigos omiten todo el verso: los minúsculos 44, 106 y 107 y Münster (NEUBAUER, Book of Tobit). 
tratándose del viaje y del matrimonio. ${ }^{14}$ Tobías le dijo que él hiciera el trámite con Ragüel para que Sara le fuera entregada. Rafael salió de la escena sólo porque Ragüel escuchó la conversación entre Tobías y Rafael y se dirigió directamente a Tobías. Tengo la impresión de que el viaje significó para Tobías algo así como un rito de tránsito de la infancia a la edad adulta, puesto que durante el viaje él asumió el mando -incluso envió a Rafael a Ragués para recoger el dinero (cf. 9,1-3), motivo del viaje- y regresó con una actitud muy diferente a la que tenía antes y durante la primera parte de éste. Por su parte, Sara debió ser una muchacha con más edad. Si había sido entregada en matrimonio, seguramente contaría ya con quince años. Pero si lo había sido siete veces, seguramente el lapso de tiempo entre una y otra boda, especialmente las últimas, no habría sido corto. Por ello me atrevo a suponer que Sara no sería una muchacha menor de 20 años. Es claro, por otro lado, que el tema de los siete maridos es sólo un recurso simbólico para mostrar el sufrimiento y el apego a las normas legales (levirato) de Sara.

La finalidad de la vida de la mujer era tener hijos y educarlos. ${ }^{15}$ Eso es precisamente lo que Sara pide en su oración; por no tenerlos habría sido insultada (cf. 3,11-15).

Tobit y Tobías sabían cuál era la situación de Sara (cf. Tb 6,14) y, seguramente, que a Tobías correspondía tomarla como esposa. Pero tampoco la práctica del levirato, que estaba estipulada en Dt 25,5-10, tenía alguna consideración para las preferencias de la mujer. ${ }^{16}$ Tobit no había dicho a los padres de Sara que Tobías no cumpliría como levir-que no se casaría con Sara-, a pesar del derecho de Sara, ni dijo a Tobías que pasara a Ecbátana para hacer pública su renuncia, siendo que, según la novela, para ir a Ragués tendría que pasar por ahí.

Otra pareja era la de Tobit y Ana, los padres de Tobías. Su relación era mucho más que espinosa. Ana mantenía a Tobit haciendo los trabajos

14 Según Tropper, "Children", 331, en la época romana, los judíos se casaban en Palestina hacia los 17 años las mujeres y 23 los varones, mientras que en Mesopotamia y Persia, entre los 15 las mujeres y 20 los varones.

15 Para el varón, la orden: "sean fecundos y multiplíquense", era un verdadero mandato. Cf. L. Yarbrough, "Parents and Children in the Jewish Family of Antiquity", Jewish Family (ed. Shaye), 39-54.

${ }^{16}$ En cierta forma tomaba en consideración las preferencias del varón, porque este podía renunciar a su derecho-obligación de cumplir como levir. 
asignados a las mujeres. Sus patrones le obsequiaron un cabrito y, al escucharlo balar, Tobit pensó que era robado y, sin más, ordenó a Ana que lo regresara. Ana le explicó que era un obsequio. Pero él no le creyó, ordenó que el cabrito fuera regresado y se irritó con ella (cf. Tb 2,14). Ana le dijo entonces algo que lo hizo sentir muy mal. He aquí el texto:

Es un regalo que me añadieron al sueldo. Pero no le creí y le insistía ${ }^{17}$ que lo regresara a los señores y estaba enfadado ${ }^{18}$ por esto con ella. Entonces me replicó: ¿Dónde están tus limosnas?, ¿dónde están tus buenas obras? Esto es sabido por ti. ${ }^{19}$

Lo cual puede interpretarse en el sentido de que Tobit hacía muchas buenas obras a los de afuera, pero Ana le reclama que no es capaz de hacerlas con ella. ${ }^{20} \mathrm{O}$ bien, podría entenderse en el sentido de que Tobit presumía de hacer buenas obras, pero la desgracia en la que vivía demostraba que no existían. Es muy posible que esta segunda interpretación sea la correcta, puesto que Ana parece representar la ceguera respecto de la voluntad y de la providencia de Dios; como la esposa de Job, que se había puesto del lado de Satán. ${ }^{21}$ De hecho, incluso Jerónimo, en su traducción, incluye una comparación entre Ana y la esposa de Job. Ana no quería, por ejemplo, que Tobías fuera al viaje a Ragués, pero ese viaje estaba en la providencia de Dios, para curar a Tobit, "curar" a Sara y lograr el matrimonio de Tobías con Sara. Además, esa queja de Ana se torna injusta y falsa, puesto que el libro inicia con una larga descripción de las buenas obras de Tobit. El insulto de Ana hizo

17 Vetus Latina PQ añaden: "que era robado".

18 Vetus Latina CPQ (C: Vaticanus, 145, Reginensis, Roma) dicen: "reñía". Vetus Latina PQ añaden: "y avergonzado". Todos los manuscritos de la Siro-Hexaplar, excepto $8 \mathrm{f1}$ (Dair as-Suryan, Syriac Ms, no 27, fol 83-94a) y 12d2 (London, Br. Mus., Add. 18.715, fol. 253b-255b) dicen que estuvo enojado; los demás dicen que estuvo avergonzado. Münster dice: "estábamos enfadados". Fagius lo omite.

19 En lugar de: "esto es sabido por ti", la Vetus Latina dice: "lo manifiesto es conocido por todos". El arameo y Münster dicen: "tu vergüenza es patente para todos". Münster antepone: "que no te benefician en el tiempo de tu desgracia". Esta última frase es diferente en los manuscritos y es difícil precisar su sentido. Zimmermann propone que hubo una lectura errónea de un original hebreo: "tu vergüenza es conocida", por: "todo por ti es conocido", del que están más cercanos B A que $S$.

20 Así piensa A. Portier-Young, "Alleviation of Suffering in the Book of Tobit: Comedy", CBQ 63 (2001) 35-54.

${ }^{21}$ De todas formas, Tobit no fue justo con Ana, lo que contradice la justicia con que, según él mismo, siempre actuaba. Este detalle no ha pasado inadvertido en la historia de la interpretación de Tobías; cf., por ejemplo, J. CousLAND, "Tobit. A Comedy in Error?", CBQ 65 (2003) 535-553. 
que Tobit se deprimiera y se deseara la muerte. Ana, a pesar de sostener económicamente a Tobit y a Tobías, no tenía autoridad para impedir el viaje de su hijo. Aunque es posible que Ana no tuviera que salir de su casa para trabajar -hacía trabajos en su casa y luego los entregaba a sus patrones-, pareciera que la aspereza de Tobit con ella se debía a que ella lo mantenía económicamente, lo cual era considerado una vergüenza (cf. Sir 25,22). ${ }^{22}$

La siguiente aparición de Ana es en 5,18-22, texto en el que afloran sus diferencias con Tobit, en relación al viaje de Tobías. He aquí el texto:

Pero su madre lloraba, y dijo a Tobit: ¿Por qué envías a mi ${ }^{23}$ hijo? ¿No es él el bastón de nuestra mano? ¿No va él y viene ante nosotros? ¡Que no preceda el dinero al dinero! ¡Que sea el precio de nuestro hijo! ${ }^{24}$ Con la vida que nos ha dado el Señor nos es suficiente. Le dijo: No hables así, sano partirá nuestro ${ }^{25}$ hijo y sano regresará a nosotros. ${ }^{26}$ Con tus ojos lo verás el día que regrese a ti sano. No hables así, ni temas por ellos, hermana, pues ${ }^{27}$ un ángel bueno lo acompañará, hará bueno su camino y lo devolverá sano.

Ana temía que su hijo muriera en el camino y recriminó a Tobit que estaba arriesgando la vida de $s u$ hijo por dinero. Notemos cómo 4Q197 y S subrayan que Ana llama a Tobías "mi” hijo, y que Tobit hace lo mismo. Más allá de que se considere que ella tenía razón o no, lo relevante para nuestro tema, es que la opinión de Ana no contó en absoluto para la decisión de Tobit. Ni siquiera la consultó. También es interesante el hecho de que ésta es la segunda vez que aparecen ambos en relación y la segunda vez que se agreden.

La tercera vez que aparece Ana en la narración es en 10,4-7:

Y Ana su mujer, dice: Murió mi hijo, ya no está entre los vivos. ${ }^{28}$ Comenzó a llorar y a lamentarse por su hijo diciendo: Ay de mí, hijo, pues te dejé partir, luz

22 Cf. COUSLAND, "Tobit".

23 B A, Vetus latina MPQ y la Siro-Hexaplar dicen: "nuestro". La Vetus Latina C, el Arameo y Fagius dicen: "al muchacho".

24 4Q197 dice: "mi hijo".

25 4Q197 dice: "le dijo, no temas, en paz partirá mi hijo". sotros".

${ }^{26}$ B A y la Siro-Hexaplar omiten: "sano partirá nuestro hijo y sano regresará a no-

${ }^{27}$ B A, la Siro-Hexaplar y Fagius omiten: "No hables así, ni temas por ellos, hermana, pues".

${ }^{28}$ B A, la Siro-Hexaplar y Fagius omiten: "ya no está entre los vivos". B A y la SiroHexaplar $8 f 1$ añaden: "pues ya pasó el tiempo". La Siro-Hexaplar 12a1 (Oo. I.I,2, fol. 
de mis ojos. Tobit le decía: Calla, hermana, ${ }^{29}$ no digas eso, está sano. Una distracción fuerte les aconteció allá. El hombre que va con él es de confianza y es uno de nuestros hermanos. No te entristezcas por él, hermana, ya vendrá. Le dijo: No me hables así, no me engañes, mi hijo ha muerto. Salía todos los días al camino ${ }^{30}$ y miraba en torno el camino que había seguido su hijo y no creía a nadie. Cuando caía el sol entraba en su casa, se lamentaba y lloraba toda la noche sin conciliar el sueño. ${ }^{31}$

Ana pensaba que Tobías había muerto y estaba inconsolable. Tobit intentó calmarla pero ella rechazó el consuelo, recriminándole que intentaba engañarla. Aparentemente, Ana se recriminaba el no haber impedido el viaje, pero en la narración correspondiente se ve que ella no tenía autoridad para haberlo evitado. El hecho de que se pasara las noches gimiendo y llorando sin poder dormir, implica que la compañía de su esposo Tobit no le servía de ningún consuelo.

Finalmente, Ana aparece en escena cuando Tobías regresa. Ana lo miró primero e informó a Tobit que "su" hijo había regresado. Acto seguido, ella fue con Tobías, dejando que Tobit la siguiera a trompicones, a causa de su ceguera. El texto es 11,5-6.9:

Ana $^{32}$ estaba sentada mirando en torno del camino de su hijo. Lo presintió llegando y dijo a su padre: Mira, tu hijo viene, junto con el hombre que fue con él.

Corrió Ana y se echó al cuello de su hijo y le dijo: Te he visto, hijo, ya puedo morir. Y lloró. ${ }^{33}$

Ana no mostró que la relación con su marido hubiera mejorado. Al advertir a su hijo, apenas dio la noticia a su esposo y lo dejó caminar

234a-236b, Cambridge, Univ. Libr.) dice: "ya no se levanta". La Vetus Latina GMPQ (G: Sangermanensis, 7, París) añaden: "¿por qué tarda?".

29 B A, la Siro-Hexaplar $8 f 1$ y el Arameo omiten: "hermana".

30 B A añaden: "para ver qué día regresaba".

31 B A omiten: "y miraba en torno el camino que había seguido su hijo y no creía a nadie. Cuando caía el sol entraba en su casa, se lamentaba y lloraba toda la noche sin conciliar el sueño". Luego añaden: "sin comer pan y por las noches no cesaba de llorar a Tobías, su hijo". La Siro-Hexaplar omite: "se lamentaba y lloraba toda la noche sin conciliar el sueño". Luego añade: "sin comer pan". La Siro-Hexaplar 12a1 añade: "pero no lo veía". La Siro-Hexaplar 8f1 añade, como B A: "y por las noches no cesaba de llorar a Tobías, su hijo".

32 Los minúsculos 44, 106 y 107 omiten los vv. 5-6. "Ana" es una adición de Fritzsche, aceptada por Rahlfs.

33 B A y la Siro-Hexaplar $8 f 1$ dicen: "y lloraron ambos". La Siro-Hexaplar 12a1 lo omite, y luego añade: "se dirigió a Tobit, su padre". Omiten: "y lloró" los minúsculos 44, 106 y 107, el Arameo y Fagius. Vetus Latina GMPQ añaden: "y también Iloró Tobías". 
solo, con su alegría, al encuentro de Tobías, mientras ella se adelantaba a abrazarlo usando una expresión más patriarcal que matriarcal -"Te he visto, hijo, ya puedo morir"- (cf. Gn 46,30). La narración no reporta ninguna reacción de Tobías ante el abrazo de su madre. La dejó y corrió hacia su padre para curarlo.

Ana, pues, era una mujer que tenía muchas diferencias con su esposo y, a pesar de que se sometía a su autoridad, le hacía sentir su distancia. Ningún texto aclara que ella lo amara, como tampoco se expresa que Tobit lo hiciese.

Al parecer, en la novela, Ana es símbolo de una mala mujer, en el sentido de que su independencia (salía a trabajar y sostenía a su marido) no podía acarrear sino problemas al matrimonio.

La tercera pareja que tiene algún papel en la narración es la formada por Ragüel y Edna. Cuando Ragüel se encontró con Tobías y con Rafael comentó a su esposa Edna que Tobías era muy parecido a Tobit (cf. Tb 7,2). Entonces Edna les preguntó de dónde eran (cf. 7,3). ${ }^{34}$ Más adelante se dice que Edna y Sara lloraron por la desgracia que había caído sobre Tobit (cf. 7,7). Después de que Ragüel entregó a Sara como esposa a Tobías, llamó a Edna y redactó el acta de matrimonio (cf. 7,13). Edna se retiró y, después de que comenzaron a cenar los varones, Ragüel la llamó para indicarle que llevara a Sara a una habitación. Ella hizo tal como Ragüel se lo había ordenado (cf. 7,15-16). Después de esto, sólo se menciona a Edna para indicar que Ragüel le mandó cocer unos panes para la fiesta de boda. Finalmente, Edna se despidió de Tobías y de Sara, después de que lo había hecho Ragüel (cf. 10,13).

Los textos muestran que Edna era una mujer de su tiempo, sumisa. Ragüel no la llamó para comentarle de las intenciones de Tobías, ni siquiera la llamó para hacer el matrimonio; sólo lo hizo para redactar el acta. Después de ello, Edna se retiró de la cena y luego fue llamada para recibir órdenes respecto de la habitación en la que debería preparar a Sara. También recibió órdenes y las cumplió, cuando se trataba de cocer unos panes. Edna asumió el cumplimiento de la ley -del levirato- ejemplarmente. Por eso, no se quejó de que Ragüel entregara a Sara sin consultarla. Ella, a diferencia de Ana, tenía una relación fluida con su

34 Vale la pena comparar Gn 29,4-6 (LXX) con Tb 7,2-5. El diálogo de Edna y la escena entera tienen la intención de recordar el encuentro de Jacob con los pastores de Labán. 
esposo, había asumido el lugar asignado para ella. Entraba en la conversación cuando le era permitido, sin problematizarla. Tal vez, esa era una de las ventajas de que no tuviera necesidad de trabajo asalariado.

Probablemente, entre Ragüel y Edna había amor y, por ello, Edna podía soportar que sus opiniones no contaran. Sin embargo, nada se dice de eso: ni de sus sentimientos hacia Ragüel, ni de los sentimientos de él hacia ella.

Visto desde nuestra concepción actual, el principal obstáculo para que hubiera amor en el matrimonio era -sin duda alguna- la situación de inferioridad en que vivía la mujer.

Analicemos ahora cómo aparece en el libro la relación amor-sexo.

Las tres parejas principales de la narración formaban matrimonios monogámicos $\mathrm{y}$, con toda probabilidad, mantenían relaciones sexuales sólo al interior del matrimonio.

De relaciones sexuales se habla sólo en el caso de Tobías y Sara, aunque con una claridad meridiana. Ellos mantuvieron relaciones sexuales sin apenas conocerse, ya casados y después de una breve oración. La esclava que entró a la habitación para ver lo que había pasado tuvo que haber advertido que ambos estaban vivos y que realmente habían mantenido una relación sexual. El texto no oculta ese detalle ni parece tomar dicho acto como algo impuro que imposibilitase la relación con Dios o la oración.

Escribiendo a los corintios hacia el año 57 d.C., Pablo afirmó que, para darse a la oración, era bueno que los esposos dejaran las relaciones sexuales (cf. 1 Co 7,5). Con esto, se acercó a la mentalidad con la que Jerónimo tradujo este libro unos trescientos cincuenta años después.

Para Jerónimo, según lo que podemos colegir por su traducción del libro de Tobías, el matrimonio perfecto no podía aceptar el deseo sexual. El deseo sexual -subrayémoslo- está presente en el matrimonio de Tobías y Sara, independientemente de que la finalidad del matrimonio fuera, básicamente, tener hijos. La exclusión de ese deseo era una perspectiva de Jerónimo, ajena al contenido del libro, y que revela otra antropología del sexo. ${ }^{35}$

${ }^{35}$ Cf. J. QueZADA, "El matrimonio y el sexo según las adiciones y las omisiones de san Jerónimo al libro de Tobías", Qol 29 (2002) 79-88. Allí concluyo que, para Jerónimo: 1) la mujer es fuente de tentación para el justo; 2) el matrimonio perfecto no acepta el deseo sexual; 3) la relación sexual causa impureza; 4) el matrimonio es indiso- 
La sujeción de la mujer tenía como finalidad evitar la exogamia, y con ella, la desintegración de la identidad del pueblo judío en la diáspora. ${ }^{36}$ Esto parece suponer que las mujeres eran más sumisas en la diáspora que en Palestina, aunque también allí debían cuidarse de la helenización.

La mujer era como un signo del exilio, en tanto que siempre estaba dependiendo de otros. Pero incluso esta significación se deja de lado para poner en primer plano la ceguera de Tobit, que pasa a ser aquí el signo.

Hay suficientes paralelos entre las historias de Tobit y de Sara como para poder sostener que el autor pudo basarse en la de Sara y, a partir de ella, construir la de Tobit. Ambos sufren injustamente (curiosamente, ninguno de los dos es completamente inocente de los reproches que recibe), son acusados injustamente, se desean la muerte, son justos, oran, son "curados" por Rafael. También son importantes los paralelos entre Tobías y Sara: ambos son hijos únicos y tienen mucha preocupación por el futuro de sus padres. En efecto, como queda patente en el capítulo 13, los males de Tobit son signo de los males del destierro, y, así como su fidelidad le produjo felicidad, así la fidelidad del pueblo lo conducirá de regreso a Jerusalén.

Ese paralelismo entre Tobit y el pueblo no se desarrolla entre Sara y los desterrados. Rompe la similitud el hecho de que Sara fuera atormentada por un demonio, en tanto que Tobit lo fuera por un ángel.

La diferente significación de las mujeres en el libro se aclara en el hecho de que sólo los varones llevan nombres teóforos: Tobit: Mi bien (es Dios); Tobías: Mi bien es Yahvé; Ragüel: Amigo de Dios; Gabael:

luble y fiel. El punto segundo, especialmente, es una perspectiva de Jerónimo ajena al contenido del libro.

${ }^{36}$ Cf. A.-J. LEVINE, "Diaspora as Metaphor: Bodies and Boundaries in the Book of Tobit", Diaspora Jews and Judaism. Essays in Honor of, and in Dialogue with A. Thomas Kraabel (eds. J. A. Overman - R. S. Mac-Lennan), (Studies in the History of Judaism 41), Scholars Press - Atlanta - 1992, 105-118. Si excluimos las veces en que se habla de las mujeres en general, en el libro de Tobías, obtenemos como resultado que la palabra se usa 28 veces, de las cuales 18 son la mujer "de", 9 son las mujeres "tomadas por", o "dadas en matrimonio a", y sólo una vez se usa sin un adjetivo posesivo (cf. 3,8 ), en donde Ragüel manda a la mujer que cueza unos panes. En todos los casos la palabra gynē puede ser traducida por esposa, excepto en 6,8 , en donde Rafael explica a Tobías qué y cómo puede curar la hiel del pez: a un varón o a una mujer. En 29 de las 30 veces en que habla de las mujeres, el autor hace alusión a que son posesiones de un varón: esposa de, tomada por, entregada a. El estudio de esta palabra constituye una confirmación, en cierta forma, de lo que hemos dicho de la situación de la mujer en el libro. 
Dios es excelso, etc., mientras que los de las mujeres recuerdan la procreación: Sara, la esposa de Abraham, madre de Isaac; Ana, la esposa de Elcaná, madre de Samuel. ${ }^{37}$ "Edna" no aparece como nombre propio en la Biblia hebrea, pero significa "placer", y es usado sólo en Gn 18,12, en donde Sara ríe y se pregunta si tendrá placer $\left(h \bar{a} y^{e} t \bar{a}-l l i\right.$ 'ednāh), ahora que ella y su marido son viejos.

La discriminación de las mujeres es más evidente porque Rafael nunca habla con Sara y parece evitarla. No se preocupa por informarle que la causa de lo que le había pasado era el demonio, ni que todo había sido una prueba de Dios, como sí explicó a Tobit (cf. 12,6-20).

\section{Tiempo y lugar de composición de Tobías}

El tiempo de composición del libro no es objeto de acuerdo, sin embargo, la gran mayoría de los estudiosos la sitúan entre los siglos iii y ii a.C. No sucede lo mismo en lo que respecta al lugar. Las propuestas van de Egipto a Mesopotamia sin que se pueda afirmar que hay mayoría declarada por una zona.

En las páginas siguientes intentaré acercarme al lugar de composición a través de la comparación de la situación de la mujer en diferentes libros (judíos) de la época. Como por este método sólo obtendremos un acercamiento a la realidad etnográfica de la mujer en las comunidades judías de los últimos tres siglos a.C., el objetivo no es llegar a una precisión absoluta del lugar de composición, sino mostrar las diferencias que hay entre este libro y otros escritos en la misma época, en Egipto y Palestina, y así contribuir al conocimiento de la realidad en que vivían las mujeres judías de aquellos tiempos y a ubicar el lugar de composición de Tobías.

\subsection{La mujer y Dios}

Como hemos visto, se suponía que la mujer no tenía capacidad para descubrir el plan providencial de Dios y de actuar en consecuencia. A este respecto es significativo que Rafael explicara a Tobit y Tobías que él había llevado la oración de Tobit y de Sara ante Dios, que había sido

${ }^{37}$ El nombre Ana está relacionado con el verbo ḥnn, hacer gracia. 
enviado para curar a ambos; y que no haya tenido la atención de decírselo a Sara (cf. Tb 12,12-14). Pero es también importante que Tb 10,12 sea probablemente la única instrucción bíblica dirigida a una mujer (Ragüel a Sara). ${ }^{38}$ Aunque Sara hizo oración y ésta fue escuchada, sólo la oración de Tobit se ocupa del pueblo y sólo su situación es comparada con la voluntad de Dios para el pueblo en diáspora. Para el autor, "los asuntos religiosos sólo conciernen al varón", "sólo los varones tienen contacto provechoso con seres sobrenaturales". 39

2 Macabeos, compuesto en Palestina hacia la mitad del segundo siglo a.C., habla de dos mujeres que circuncidaron a sus respectivos hijos y que por ello fueron asesinadas (cf. 2 Mac 6,10). Más adelante, en el capítulo 7, narra largamente la hazaña de una mujer que, en un solo día, vio morir a sus siete hijos y que animó al más pequeño a que no se desdijera de su fe. Aunque es cierto que en ese libro las mujeres tienen un papel muy secundario, a veces son presentadas como heroínas que comprenden lo que Dios pide de ellas y lo llevan a la práctica.

De la misma época, y también escritos en Palestina, son Judit y Ester. ${ }^{40}$ En ambos libros, las protagonistas comprendieron la voluntad de Dios y arriesgaron su vida para hacerla. Aunque Ester tuvo la guía de su primo Mardoqueo, ella comprendió bien lo que debía realizar para cumplir con los designios de Dios. Estos casos contrastan con los de Ana, Sara y Edna, las mujeres que aparecen en Tobías.

Si retrocedemos un poco en el tiempo, nos encontramos con el libro Qohélet, que habla con cierto desprecio de la mujer. Afirma, por ejemplo, que la mujer es más amarga que la muerte (cf. Qo 7,26); que entre todas ellas no encontró a una (verdadera mujer) (cf. Qo 7,28). Sólo en Qo 9,9 parece tener una mirada amable hacia ella: "vive la vida con la mujer que amas". Sin embargo, fuera de este texto, el libro no menciona el amor hacia la mujer o la esposa como algo significativo en la vida del varón, por ejemplo, cuando pone los famosos dísticos de su soneto (cf. Qo 3,1-8) y cuando repasa las incapacidades de la vida anciana (cf. Qo 12,1-7). En contraste con Tobías, Qohélet no parece tener ningún aprecio

38 Así, B. WoLD, "Family Ethics in 4QInstruction and the New Testament", VT 50 (2008) 286-300, nota 21.

39 B. Bow - G. NiCKELSBURG, "Patriarchy with a Twist: Men and Women in Tobit", Women Like This (ed. Levine), 127-143 (esp. 143.134).

40 Judith y Ester (gr.) pudieron haber sido escritos durante la primera mitad del siglo I a.C. 
por el matrimonio y prácticamente no tiene en cuenta a la mujer. Al parecer, no tenía intención de instruir a sus destinatarios sobre el control que debían ejercer sobre ella, como hace el autor de Tobías.

El Libro de los jubileos, ${ }^{41}$ revela una situación muy diferente a la de Tobías. En él, varias mujeres toman papel protagónico, conocen la voluntad de Dios y actúan de acuerdo con ella. Rebeca es advertida en sueños que Esaú quiere matar a Jacob $(27,1)$ y luego habla con Isaac para que este obligue a Esaú a jurar que no hará daño a Jacob $(35,19)$. "La preferencia de Rebeca por Jacob recibe legitimación patriarcal, ética y teológica". ${ }^{42}$ Un tratamiento similar hacia la mujer, tienen las Antigüedades Bíblicas, del Pseudo Filón, para quien las mujeres "son instrumentos y agentes activos de Dios". ${ }^{43}$ La historia de José y Aseneth ${ }^{44}$ dice que Aseneth tenía, como Rebeca en los Jubileos, experiencias revelatorias de Dios (15,1-7). En Vida de Adán y Eva, ${ }^{45}$ ella no tiene

${ }^{41}$ El Libro de los jubileos fue escrito en Palestina; según R. H. Charles, entre 135105 a.C.; según A. DíEz MACHO, Apócrifos del Antiguo Testamento I: Introducción general, Cristiandad - Madrid - 1984, 180, entre 109-105 a.C.; mientras que F. Corriente - A. Piñero, "Libro de los jubileos", Apócrifos del Antiguo Testamento II (ed. A. Díez Macho), Cristiandad - Madrid - 1983, 67-193, sitúan la redacción entre 140 y 105 a.C. Entre los apócrifos, el más importante para el estudio de Tobías, por otros motivos, es la Historia de Ajicar, que, sin embargo, no es judío ni habla de las relaciones familiares judías. La Historia de Ajicar pudo haber sido escrita en el siglo V a.C., según E. Martínes, "Libro arameo de Ajicar", Apócrifos del Antiguo Testamento III (ed. A. Díez Macho), Cristiandad - Madrid - 1984 y HaRRIS - ReWIS - WonYBEARE, Apocrypha and Pseudoepigrapha of the Old Testament II (ed. R. Charles), Oxford University Press Oxford - 1963, 715-784.

42 R. CHESNUTT, "Revelatory Experiences Attributed to Biblical Women in Early Jewish Literature", Women Like This (ed. Levine), 107-125.

43 B. Halpern-Amaru, "Portraits of Women in Pseudo-Philo's Biblical Antiquities", Women Like This (ed. Levine), 83-106. Se trata de un texto muy difícil de datar, pero que está familiarizado con el Libro de los Jubileos. La mayoría de los autores piensa que es una obra posterior al 70 d.C., según A. DE LA FUENTE, "Antigüedades Bíblicas", Apócrifos II (ed. Díez Macho), 197-208. En relación con el varón, por otro lado, y tratándose de mujeres no caracterizadas por el Libro de los Jubileos, las Antigüedades Bíblicas describen a la mujer como dependiente e "inefectiva".

44 José y Aseneth fue escrito durante el primer siglo a. C., según CHESNUTT, "Revelatory Experiences", Women Like This (ed. Levine). Según el autor, esta obra tenía la finalidad de apoyar los matrimonios de judíos con prosélitos.

${ }^{45}$ La Vida de Adán y Eva es una versión latina, en muchos puntos distinta, de la Vida de Adán y Eva en griego, conocida como Apocalipsis de Moisés. Fue escrita en diferentes épocas, pero es muy posible que el texto base fuera redactado entre el 300 y el 60 a.C., según Wells, o tal vez un poco después. Wells afirma que fue escrito en Alejandría. Collins dice que proviene de los siglos I-II d.C. A. DíEZ MACHO, "Vida de Adán y Eva", Apócrifos I, 195, dice que fue escrito antes del 70 d.C. Lo mismo afirma N. Fernández, "Vida de Adán y Eva", Apócrifos II (ed. Díez Macho), 319-352. 
ningún entendimiento de la voluntad de Dios. El libro parece haber sido escrito para culparla del pecado del paraíso, pues insistentemente se afirma que ella fue quien pecó (cf. 3,$2 ; 5,3 ; 9,1-5 ; 10,1-4 ; 16,1-4 ; 18,1$; 33,3; 35,2.3; 37,2; 44,1-5; Apocalipsis de Moisés 7,2-3; 15,1; 21,4-5; $21,6 ; 32,1-4 ; 35,6)$. Pero también en esa línea está el hecho de que Eva no comprendiera la invitación a la penitencia que le hizo Adán (cf. 5,3), y la petición de la misma Eva para que Adán intercediera por ella (cf. 20,1-3). Además, cuando fue el entierro celestial de Adán, ella dormía (Apocalipsis de Moisés 42,3). El Apocalipsis de Moisés intenta una defensa de ella en 39 (contra Vida de Adán y Eva 10,1-4), en donde afirma que Eva no creyó a la segunda tentación del Satán. En este rubro, la mujer tiene aún menos capacidad de diálogo con Dios que el que se muestra en Tobías, pues ahí Sara hace oración sin necesidad de intercesión de varón.

El Testamento de los doce patriarcas ${ }^{46}$ nunca habla de posible contacto o revelación de Dios a alguna mujer. Los destinatarios de visiones y de promesas son sólo los varones, mientras que ella es fácil presa del espíritu de fornicación (cf. Rub 5,3). En la misma línea está el Libro de los secretos de Henoc ${ }^{47}$ (2 Henoc), en donde se dice que Satomail hizo mal a Adán por medio de Eva, a quien sedujo, pues a Adán no lo tocó (cf. 31,6). Esto tiene cierta consonancia con Tobit, pues él hizo lo que Dios esperaba de él, mientras que Ana se oponía.

Un tratamiento más amplio de este tema se encuentra en 4 Macabeos, ${ }^{48}$ que elogia mucho a la madre de los siete hermanos, junto con quienes ella sufrió el martirio. Ella fue virtuosa (cf. 1,8); no se dejó

${ }^{46}$ El Testamento de los doce patriarcas fue escrito al final del segundo siglo a.C., cf. J. Coluins, Between Athens and Jerusalem, The Biblical Resource Series, Grand Rapids/Cambridge - 2000. A. PIÑERO, "Testamentos de los doce patriarcas", Apócrifos IV (ed. Díez Macho), Cristiandad - Madrid - 1984, 11-158, dice que el escrito básico debió haber sido hecho entre el 200 y el 174 a.C.

47 El Libro de los secretos de Henoc fue escrito entre el 30 a.C. y el 70 d.C., según N. Forbes - R. H. Charles, "2 Enoch, or The Book of the Secrets of Enoch", Apocrypha II (ed. Charles), 425-469. A. Díez MACHO, "Libro de los secretos de Henoc (2 Henoc)", Apócrifos I, 241, opina que fue escrito hacia el 70 d.C., aunque con adiciones posteriores. De la misma opinión es A. De SANTOS, "Libro de los secretos de Henoc", Apócrifos IV (ed. Díez Macho), 145-202.

484 Macabeos fue escrito entre el 63 a.C., y el 38-39 d.C., según R.B. TownSHEND, Apocrypha II (ed. Charles), 653-685. Sin embargo, parece que actualmente se prefieren fechas más tardías, que irían del 18 a.C. al inicio del tercer siglo d.C. (ver, por ejemplo, M. D'Angelo, "Ev̉ó́ $\beta \in \iota \alpha$. Roman Imperial Family Values and the Sexual Politics of 4 Maccabees and the Pastorals", Biblnt 11 (2003) 139-165, nota 3. 
vencer en la prueba, por el amor a sus hijos (cf. 14,20), por lo que prefirió la muerte (cf. 15,2-3.8.32; 16,1); incluso los impulsó a ser fieles (cf. $15,11$ ); debido a que era guiada por la piedad (tèn eusébeian 15,14$) ;{ }^{49}$ por lo que se puede decir que el fruto de su vientre fue la religión perfecta (tè̀n eusébeian holóklēron 15,17); era una madre guerrera de Dios (cf. $16,14 ; 17,11-12)$; se la compara con Daniel y los tres jóvenes que fueron metidos al horno de fuego (cf. 16,3), e incluso con Abraham (cf. 16,1920). Ella está en la vida eterna por haber dado ejemplo de la fe nobilísima que la animaba (cf. 17,2-5; 18,23).

El Pirke Abot ${ }^{50}$ alerta en contra de la esposa, pues hablar mucho con ella hace daño al marido (cf. 1,5) y conduce a brujerías (cf. 2,5).

Una instrucción encontrada en Qumrán -4QInstrucción-, escrita hacia 250 a.C., insiste, fundamentada en Gn 2-3 y en el quinto mandamiento, en que el varón debe dominar a la mujer. ${ }^{51}$ Esta instrucción (cf. 4Q415, 416, 417, 418, 423) es el trabajo sapiencial más largo encontrado en Qumrán. No personifica a la sabiduría en una mujer -como 4Q184, 185, 525-, y habla poco de la situación real de la mujer para los esenios. $^{52}$

Al parecer, Tobías no fue escrito ni en Palestina ni en Egipto (Alejandría), en los siglos II-I a.C. Pues 2 Macabeos, Judith, Esther, Jubileos, la Vida de Adán y Eva, y el Apocalipsis de Moisés, no tienen afinidad con lo que Tobías afirma con respecto a las relaciones de las mujeres con Dios.

Si Qohélet fue escrito en Palestina hacia el final del tercer siglo y el principio del segundo a.C., me parece que sería prudente poner la

49 Esa palabra, tan importante para describir las virtudes domésticas y religiosas en 4 Macabeos y en las pastorales, no es usada en Tobías.

50 Según R. Herford, "Pirke Abot", Apocrypha II (ed. Charles), 686-714, este libro fue recopilado por $\mathrm{R}$. Judah, pero a partir de dichos muy antiguos. En 1,5 se transmite la enseñanza de Jose ben Jojanan de Jerusalén, y en 2,5 la de Hillel, quien vivió en los tiempos de Jesucristo.

${ }^{51}$ Ver Wold, "Familiy", donde explica que 1 Co 11; Ef 5 y 1 Tm 2, junto con 4 QInstrucción, tienen como trasfondo Gn 2-3 y el quinto mandamiento, y que Filón pudo haber sido influenciado por esta última.

52 B. WRIGHT II, "Wisdom and Women at Qumran", DSD 11 (2004) 240-261, dice que 4Q184, 185, 525, pudieron haber sido escritos en el segundo siglo a.C., y ser, junto con $4 Q$ Instrucción, pre-qumrámicos. A pesar de ello, su influencia entre los esenios se revela por las copias que ellos realizaron. 
composición de Tobías antes de él, o bien, lo que parece más probable, en un lugar de la diáspora, pero no en Egipto.

En cuanto a los Salmos de Salomón ${ }^{53}$ y los Fragmentos de una obra sadoquita, ${ }^{54}$ su interés por la pureza cultual difiere bastante de lo narrado en Tobías, por más que la mujer parezca tener más o menos la misma relación con Dios.

El Testamento de los doce patriarcas, Libro de los secretos de Enoc, y Pirke Abot, reflejan una cultura en la que la mujer no puede tener relación con Dios, sino de manera muy precaria, siempre subordinada al varón. Estos libros coinciden con lo que se puede colegir de Tobías, sin embargo, parecen bastante tardíos. El caso de 4QInstrucción es bastante coincidente con Tobías, y su datación parece que puede remontarse al siglo II a.C., o antes.

En conjunto, Tobías parece desentonar entre estos libros -en cuanto a la relación de la mujer con Dios-, por lo que es prudente pensar, guiados por este tema, que no fue escrito en Palestina o Egipto.

\subsection{La mujer y el varón}

En el contexto bíblico, a pesar de textos como Gn 2,18-24, que hablan de una igualdad fundamental entre varón y mujer, ella estuvo siempre, de hecho, bajo la tutela del varón, ya fuera su padre o su marido. En los relatos patriarcales del Gn, se observa una marcada autoridad del marido sobre la esposa o del padre sobre sus hijas. ${ }^{55}$ En las épocas de los jueces esa dependencia no mejoró sustancialmente, pero las legislaciones posteriores le otorgaron cierta protección. ${ }^{56}$ La predicación profética, al comparar a la mujer con Israel, contribuyó a su dignificación. Aunque

53 Escritos alrededor del año 50 a.C., según G. GRAY, Apocrypha II (ed. Charles), 625-652. A. Díez MACHo, "Salmos de Salomón" Apócrifos I, 205-208, opina que el 40 d.C. en ellos se afirma que la sangre menstrual hace impuro cualquier sacrificio $(8,13)$.

54 En los Fragmentos de una obra sadoquita [escritos, según CHARLES, "The Fragments of a Zadokite Work", Apocrypha II (ed. Charles), 785-871, entre el 18 y el 8 a.C.], se dice que no está permitido tener relaciones sexuales los sábados en Jerusalén, pues eso hace impuro al santuario (cf. 14,4), y que los votos que hubiera hecho una mujer deben invalidarse, según lo que había dicho Moisés (cf. 20,7).

${ }^{55}$ Cf., por ejemplo, Gn 12,10-20; 19,1-9; 20.

${ }^{56}$ Por ejemplo, la institución del mohar, o cantidad que el novio dejaba como depósito para protección de la mujer, en caso de ser repudiada (cf. Gn 34,12; Ex 22,16); o la prohibición de repudiar a una mujer a la que se había violado o seducido (cf. Dt 22,28-29), etc. 
libros sapienciales elogian a la mujer sabia, prudente y trabajadora, siguió estando en una situación de inferioridad notoria con respecto al varón.

El ideal de familia y los valores familiares de Tobías coinciden ampliamente con los del Génesis, libro que constituye como su modelo. ${ }^{57}$ En suma, como dice Nickelsburg: "Una vez más ella es objeto; él es sujeto. Incluso el cielo mira aquí a Sara como commodity". ${ }^{58}$

El autor de Tobías, empero, no daba a la procreación más importancia que a la fidelidad y a la monogamia, ${ }^{59}$ pues para él, el matrimonio debía implicar fidelidad de ambos cónyuges y monogamia. Asuntos que no tienen relevancia en los relatos aludidos. La limosna es, en el libro, un asunto de varones. La mujer, aunque tenga bienes, no puede disponer de ellos para dar limosna mientras su padre o su marido vivan. La herencia de Sara fue entregada a Tobías; la primera mitad cuando regresó a Nínive y la otra cuando murieron los padres de Sara. El enterramiento de los padres era, también, responsabilidad de varones, pues Tobías sepultó incluso a sus suegros.

En general, todos los libros del Antiguo Testamento dan cuenta claramente de esa sumisión, y Tobías no es la excepción. Se distinguen un poco de esa corriente Judit, Ester y Rut. Judit y Ester griego proponen que la mujer puede tener un rol más activo, e incluso de gobierno, en la sociedad. En esas dos historias, como en la de Susana, un varón potentado falla en su intención de seducir a una mujer virtuosa. Ninguna

57

Cf. I. NowELL, "The book of Tobit. An Ancestral Story", J. CORELY - V. SKEMP, Intertextual Studies in Ben Sira and Tobit, CBQ.MS 38, Washington - 2004, 3-13. Sobre todo por los viajes del siervo de Abraham, Jacob y José. S. WeitzMAn, "Allusion, Artifice, and Exile in the Hymn of Tobit", JBL 115 (1996) 49-61, nota que esos viajes son aludidos en Tobías porque reflejan la situación de Israel fuera de su tierra y la esperanza de un retorno dichoso. La relación de Tobit con Ana es antigenesíaca porque Ana sostenía a Tobit, contra la situación establecida por Dios en Gn 3,16.19. También el hecho de que Sara no pudiera engendrar estaba en contra del mandato de ser fecundos de Gn 1,28. Además de esto, la comparación de Tobías con Gn 24 es significativa (Abraham envía a buscar, entre sus parientes, una esposa para su hijo Isaac; un ángel juega un rol importante).

58 B. Bow - G. NiCKElsburg, "Family", Women Like This (ed. Levine), 127-143

59 D. Petersen, "Genesis and Family Values", JBL 124 (2005) 5-23, dice que el Génesis es literatura de familia porque 1) tiene genealogías realistas; 2) trata de ritos familiares; 3) se ocupa de conflictos intrafamiliares y 4) describe relaciones familiares en forma horizontal y vertical. El autor no relaciona estas características con Tobías, pero la semejanza es sorprendente y se puede, según esto, calificar Tobías como literatura de familia - sin negar el carácter paradigmático de los personajes-. 
de esas tres historias está en Qumrán, tal vez debido a su tendencia farisaica. Es posible que hayan sido usadas como propaganda para sustentar el reinado de Salomé Alejandra (76-67) en Palestina. En los tres casos la mujer queda, aún después de sus hazañas, inmersa en un mundo patriarcal (su feminismo es relativo). ${ }^{60}$ En Tobías, Sara es la única mujer elogiada: "es prudente, valerosa y muy bella" ( $\mathrm{Tb} 6,12)$, cualidades muy similares a las que tenían Judit y Ester (cf. Jdt 8,6; 10,7.19.23; 11,21; Est $2,3.17 ; 5,1$ ), pero Sara se queda atrás, porque no es sabia (cf. Jdt 8,29; $11,20-21)$ y nunca es protagonista. En eso también contrasta con la madre de los siete mártires, que aparece en 2 Mac 7. Las precauciones que propone el Eclesiástico, contrastan con la situación de sujeción que se respira en Tobías. ${ }^{61}$ Sin embargo, hay coincidencias bastante claras. Por ejemplo, el hecho de que la mujer acepte cualquier marido (cf. 36,21), el que lo mejor sea vivir marido y mujer (cf. 40,23); el que es una vergüenza que una mujer mantenga a su marido (cf. 25,22); el que por ella haya empezado el pecado (cf. Sir 25,24). Para el Sirácide, el hecho de tener una buena o mala esposa redunda en la gloria del marido (cf. Sir 26,1-4), por ello, el marido debe tener control sobre ella, especialmente sobre su sexualidad (cf. 33,20; 25,25; 42,6). ${ }^{62}$

Eva Cantarella afirma que la situación de la mujer en el helenismo mejoró notablemente con respecto a las épocas anteriores. Ellas podían comprar, vender, prestar y recibir préstamos, trabajar, hacer testamentos y recibir herencias e incluso, aunque sólo en algunos casos, elegir marido. ${ }^{63}$ Ello implicaba que el matrimonio podía ser realizado por amor.

60

Cf. D. Clanton, "(Re)dating the Story of Susana. A Proposal", JSJ 34 (2003) 121-140, en donde habla de qualified feminism. Su artículo pretende situar la composición de Susana en el tiempo y en el espacio, ayudado por las relaciones de género que ahí se expresan.

61 Por ejemplo: "¿Tienes hijas?, vigila su cuerpo y no seas indulgente con ellas" $(7,24)$; "No tengas celos de la mujer que amas, no sea que tú la enseñes a actuar contra ti" $(9,1)$; "No te entregues del todo (no te apasiones por) a tu mujer, no sea que te llegue a dominar" $(9,2)$; y las cautelas para ir con prostitutas o adúlteras (cf. 9,3-7; $25,20 ; 41,22.24)$; o las advertencias contra la mujer borracha, adúltera o atrevida (cf. 26,8-10).

${ }^{62}$ C. CAMP, "Women in Second Century Jerusalem Through the Eyes of Ben Sira", Women Like This (ed. A.-J. Levine), 1-25, relaciona las características básicas de la antropología mediterránea (honor-vergüenza), con el Sirácide, y encuentra coincidencias sorprendentes. El control de la mujer se extiende, por obvias razones, a las hijas (cf. 7,24-25; 22,3-6; 42,9-14).

63 Cf. E. Cantarella, Daughters. The Role and Status of Women in Greek and Roman Antiquity, John Hopkins University Press - Baltimore / Londres - 19934, 91. En la 
En Egipto, las mujeres tenían un margen mucho mayor de libertad y de actuación en la vida política desde tiempo atrás. Evidentemente, no podemos trasponer todas esas conquistas a las comunidades judías, ellas tenían, en gran parte, un ritmo propio, además de que, como he dicho, no todas las comunidades de la diáspora marchaban al parejo. La comunidad de Elefantina es un buen ejemplo de ello. Entre los siglos V y IV a.C., se percibe en ella que el matrimonio era un contrato en el que la mujer tenía garantizada la posibilidad de pedir el divorcio, administrar sus bienes e incluso exigir ser la única esposa.

En el Libro de los Jubileos, la mujer tiene un papel más importante en la relación con el varón, es "co-igual". ${ }^{64}$ Casi se puede afirmar que Rebeca, por ejemplo, fue la protectora de Jacob. Ella recomendó a Isaac que lo cuidara (cf. 25,1-3) y luego ella misma lo bendijo (cf. 25,15-23); como también hizo, después, con Leví y con Judá (cf. 31,7). Lía, la esposa de Jacob, era amada por todos y fue muy llorada a su muerte (cf. 36,20-24). En el libro se dan los nombres de las esposas de los hijos de Jacob (cf. 34,20). En ocasiones quita culpabilidad a la mujer, por ejemplo, dice que Bilhá, la concubina de Jacob, fue violada por Rubén mientras dormía; y Dina, tenía sólo doce años cuando cayó en un engaño tramado por Siquem (cf. 30,2). ${ }^{65}$ La Vida de Adán y Eva insiste en la superioridad de Adán, tanto que queda casi descargado de responsabilidad del pecado en el paraíso. Joel regaña a Adán (cf. Apocalipsis de Moisés 32,4), por haber hecho caso de Eva, en lugar de haberla sometido, pues para eso había sido creada (cf. 26,1-2). Ella es bendecida a causa de Adán (cf. 21,2). Sin embargo, Eva toma ciertas iniciativas, aunque sólo en el Apocalipsis de Moisés: hace ver a Set el entierro celestial (cf. 35,2); presiente su muerte (cf. 49,1); y manda que sus hijos escriban lo que ella y Adán les habían contado (cf. 50,1-2). La

página 96 reporta un epitafio escrito por Leónidas hacia el 300 a.C. para una mujer que había sido borracha, y luego una invectiva de Meleager, escrita hacia el 100 a.C., dirigida a una prostituta borracha. Esa libertad de las mujeres en el helenismo pudo infiltrar las costumbres judías (cf. Sir 26,8).

64 B. HALPERN, "The First Woman, Wives, and Mothers in Jubilees", JBL 113 (1994) 609-626, resalta que en Jubileos, Eva se cubrió primero que Adán (cf. 3,21), menciona los nombres de las hijas de Adán y Eva, y une menos a Eva con Caín.

65 Según G. NickelsburG, "Tobit, Genesis and the Odissey", Mimesis and Intertextuality in Antiquity and Christianity (ed. H. Macdonald), Trinity Press International, Philadelphia - 2001, 48-51, el autor de Jubileos conoció y usó Tobías. El v. 12 parece decir que en el paraíso no había relaciones sexuales (por motivos de pureza), mentalidad que se encuentra también en algunos documentos del Mar Muerto. 
situación de la mujer, con respecto al varón es, en este libro, muy similar a la que se ve en Tobías.

En la Carta de Aristeas $^{66}$ se habla muy poco de la mujer, eso revela que no tenía un rol importante en la vida política de la diáspora alejandrina. En 250 parece presuponerse la monogamia. Ahí se aconseja no provocar a la esposa para vivir amigablemente con ella. Se dice que es testaruda y débil. Coincide con el caso de Tobit y Ana, en cuanto que Tobit parece haber provocado a Ana y eso le causó una gran pena. Fuera de esa breve alusión, la mujer pasa completamente inadvertida.

El Testamento de los doce patriarcas afirma que la mujer puede ser muy poderosa dentro de casa y advierte a los varones para que no le den poder. Ella puede seducirlo y cautivarlo: Rub 5,2-4.6; Jud 15,5-6 incluso gobernar sobre los matrimonios de sus hijos: Jud 10,1-6; 11,1-5. En general, la mujer es mala y es un tropiezo: Rub 5,1; Jud 17,1; Is 4,4. Por ello, el varón debe huir del placer con las mujeres: Is 3,5; Jos 10,2; pero también la mujer debe huir del placer con los varones: Is 2,1 (Raquel deseaba a Jacob sólo por engendrar de él), sobre todo, antes de casarse Rub 4,1; 6,2; Lev 9,10; pues Dios ama la castidad: Lev 9,10; Jos 10,3. Se habla bastante de las mujeres, aunque siempre como esposa y madre: Lev 11,$1 ; 12,4 ;$ Jud 8,2; Nef 1,10; Ben 1,3-5. Del amor... sólo se menciona el que Jacob tenía por Raquel: Ben 1,5, aunque en Is 5,3 y 6,2 él exhorta a sus hijos a ser buenos y trabajadores para sus esposas. Del amor filial, sólo se dice que Judá se enorgulleció de haber honrado a su madre y a Raquel: Jud 1,5. Un texto interesante para el tema que nos ocupa es Nef 8,8 , en donde se dice que, para el varón, hay tiempo de abrazar a su esposa y tiempo de abstenerse para orar. Esa afirmación está en franca contradicción con $\mathrm{Tb}$ 8,4-8. Josefo decía que la relación sexual sólo debía realizarse con miras a la procreación. ${ }^{67}$

En el III Oráculo sibilino ${ }^{68}$ se habla muy poco de mujeres. En los vv. 75-81 la sibila se lamenta del tiempo en que el mundo estará bajo el

La Carta de Aristeas fue escrita hacia la mitad del segundo siglo a.C. Collins dice que entre 145-125; Andrews, que entre 130-70 a.C. Fue escrita en Alejandría.

67 F. JOSEFo, Ap. 2,199.

68 El III oráculo sibilino fue escrito, según O. LANCHESTER, "The Sybilline Oracles", Apocrypha II (ed. Charles), 377-406, entre el 176 a.C. y el 84 a.C. Collins, Between, como la mayoría, piensa que fue escrito en la segunda mitad del segundo siglo a.C. A. Díez MACHo, "Oráculos Sibilinos", Apócrifos I, 223, opina que fue escrito en el segundo siglo a.C. 
dominio de una mujer, pues, entonces, todo quedará abandonado. En el v. 480 se lamenta de las muchachas que van a morir y en el v. 785 exalta a la virgen por cuyo medio el Altísimo ha dado vida eterna. Aunque pocas veces, se condena el adulterio y la impureza sexual (cf. 203; 294; 357; $359,764)$; junto con algunas menciones de las relaciones pedófilas y zoófilas (cf. 596-599, 764). El papel de la mujer como profetisa, aunque parece una concesión a la cultura pagana, le da una preponderancia que no tiene en las historias narradas en los Oráculos sibilinos $I V$ y $V .{ }^{69}$

El IV Macabeos trata ampliamente de una mujer, la madre de los siete jóvenes martirizados. Se encarece su labor en el embarazo y en la educación de los hijos (cf. 10,2; 14,13; 15,5-7.9-10). Destaca que ella parece ser la encargada de la circuncisión de sus hijos (cf. 4,24). Se elogia su valor durante la ejecución de los muchachos (cf. 1,10; 8,4; 12,6; $14,12 ; 15,20.24 .29 ; 16,6-7 ; 17,1)$. Hay algunos versículos que reflejan varios aspectos interesantes de la situación de la mujer en aquella época: el varón la podía castigar (cf. 2,10-11); era una afrenta que un varón la tocara (cf. 17,1); no debía salir de la casa de su padre (cf. 18,7); debía cuidarse de la seducción y del adulterio (cf. 18,7). ${ }^{70}$ También PseudoFocílides decía que no debía salir de su casa hasta casarse. ${ }^{71}$

El Pirke Abot habla muy poco de la relación varón-mujer, aclara que el matrimonio se acostumbraba a los 18 años (cf. 15,27). Sobre el amor, dice que debe ser incondicional, pone dos ejemplos, uno de amor

69 Estos oráculos quedan fuera de nuestra consideración por datarse más tardíamente. El IV oráculo sibilino, según LANCHESTER, "The Sybilline", Apocrypha II (ed. Charles), 377-406, puede datarse entre los años 76 y 80 d.C. DíEZ MACHO, "Oráculos Sibilinos", Apócrifos I, 224, opina que fue escrito hacia el 80 d.C. En cuanto al V oráculo, para LANCHESTER, "The Sybilline", Apocrypha II (ed. Charles), 377-406, hay que datarlo hacia el 130 d.C. Lo mismo piensa Coluins, Between. En cambio, Díez MACHO, "Oráculos Sibilinos", Apócrifos I, 225, opina que fue escrito antes de la guerra de Bar Kokhba (132-135 d.C.).

70 En este libro se exalta a la madre y casi no se menciona a ningún padre, como notó D'ANGELO, "Ev̉ó́ $\beta \in L \alpha ", 156$. El padre, señala ella, es mencionado sólo como ga-

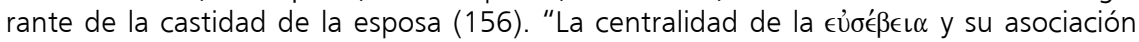
con los deberes familiares, lo que se refiere a la seguridad de la madre con respecto al stuprum y al adulterio, su matrimonio por la duración de su fertilidad, su sumisión a las órdenes de su marido: todo eso sugiere que ambas, la legislación social Augusta y la propaganda imperial que la acompañaba, ha tenido algo que ver en esta narración $[\ldots]^{\prime \prime}(157)$.

71 Pseudo Focílides 215-216, según Coluıns, "Marriage", 143. 
condicionado, el de Ammón y Tamar, y uno incondicionado, el de David y Jonatán (cf. 5,19). ${ }^{72}$

Los Fragmentos de una obra sadoquita extiende a las mujeres la norma expresada para varones. Una mujer no debe acostarse con el hermano de su padre (cf. 7,11). Retoma la norma de que un sacerdote no debe casarse con una viuda (cf. 8,12), e insiste en que se debe tomar mujer conforme a la ley (cf. 9,1).

Tobías guarda cierta diferencia con respecto a los demás libros bíblicos, pues ninguno revela tanta sujeción para la mujer, ni siquiera el Sirácide, con el que tiene muchas coincidencias. Jubileos y el 4 Macabeos son francamente muy diferentes de Tobías, en cuanto a la relación varón-mujer. Varios libros revelan que esas relaciones tenían patrones bastante generalizados, entre ellos: Carta de Aristeas, III Oráculo sibilino, Asunción de Moisés, Libro de los secretos de Enoc, ${ }^{73}$ IV Esdras, ${ }^{74}$ Pirke Abot, y Fragmentos de una obra sadoquita. La Carta de Aristeas presenta, en este rubro, un buen ejemplo de consonancia con Tobías. El III Oráculo sibilino parece destinado a criticar el dominio de la mujer en el campo político, tema del que Tobías parece bastante alejado. Asunción de Moisés, Libro de los secretos de Enoc, IV Esdras, y Pirke Abot tienen afirmaciones demasiado generales sobre el tema. Fragmentos de una obra sadoquita, da prescripciones cultuales y legales.

El Testamento de los doce patriarcas tiene también ese punto en común con Tobías, pero la afirmación de Nef 8,8 es determinante para considerarlos obras de ambientes diferentes.

\footnotetext{
72 Según Herford, "Pirke", Apocrypha II (ed. R. Charles), el capítulo 5 fue añadido por R. Judah.

${ }^{73}$ La Asunción de Moisés (escrito durante el primer tercio del primer siglo de la era cristiana, según R. CHARLES, "The Assumption of Moses", Apocrypha II (ed. Charles), 407-424. No habla de mujeres, ni refiriéndose a la historia de Israel ni al presentar listas de pecados. La única mención está en 11,12, en donde Josué se compara con un padre o una madre (Israel con su hija), a la que debe cuidar y presentar virgen al esposo al que deberá reverenciar. En el Libro de los secretos de Henoc se menciona muy pocas veces a la mujer, pero es significativo que en $31,17.18$ se diga que fue hecha precisamente como esposa y madre, en consonancia con Tobías.

74 El IV Esdras (escrito entre el 30 a.C. y el 120 d.C., según G. Box, "IV Ezra", Apocrypha II [ed. Charles], 542-624. A. DíEz MACHO, "Libro 4 de Esdras", Apócrifos I, 250, opina que fue escrito después del 70 d.C.) sólo habla de la mujer tangencialmente. En $4,40.42 ; 5,46.50$ es quien puede tener hijos. Casi lo mismo se puede decir de 9,$38 ; 10,1-44$, en donde se compara a Sión con una mujer que llora a un hijo muerto.
} 
En conclusión, la situación de sujeción de la mujer era algo generalizado en el judaísmo. Ciertamente, Tobías comparte este patrón. Sin embargo, parece prudente no situar la composición de Tobías en Jerusalén, Egipto ni Asia Menor, lo cual nos lleva a Mesopotamia o Persia.

\subsection{El levirato}

En este libro, el levirato toma unas características que no tiene en el resto del Antiguo Testamento. Esto puede también ayudar a situar el lugar de composición.

a. En primer lugar, en Tobías se deja de lado la preocupación por la preservación del nombre del difunto, para centrarse en el matrimonio endogámico y en la conservación de los bienes dentro de la familia. Ninguna de esas dos motivaciones estaba en la ley que regulaba el levirato (cf. Dt 25,5-10).

Veamos esto con mayor detenimiento. En Gn 38 se narra la historia del matrimonio de Tamar con dos de los tres hijos de Judá y cómo este decidió quemarla por no haber guardado fidelidad a su tercer hijo, Sela. Hay cierto paralelismo entre Sara y Tamar, pues, en ambos casos, después de varios matrimonios, tendrían descendencia de un levir.

Tal vez la ley no se limitaba, en un principio, a los cuñados, sino que era una institución del clan, como se ve en la historia de Rut, que no tenía cuñados (cf. Rut 1,11-12); o bien, tuvo que extenderse a otros parientes posteriormente. En Rut se mezclan dos instituciones. Por un lado, la necesidad del rescate de la tierra para evitar la enajenación del patrimonio, tal como se manda en Lv 25,23-25. Y por otro lado, el levirato. ${ }^{75}$

Los matices que tiene Tobías con respecto al levirato son fundamentales. Estos pueden haberse originado en un contexto en el que lo más urgente era que la comunidad judía conservara su identidad (matrimonio endogámico) y sus pertenencias. Por ello, me atrevo a pensar que la comunidad destinataria del libro vivía en la diáspora, en una comunidad en la que la identidad judía estaba en riesgo, era una

75 Rut 4,10 dice: "y de que también he adquirido a Rut, la moabita, viuda de Majalón, para conservar el apellido junto con la propiedad del difunto y para que su nombre esté siempre presente entre sus hermanos cuando se reúnen a la entrada de la ciudad". 
comunidad pequeña, que podía interpretar y adaptar la ley de Moisés con cierta libertad. Como propuse, creo que dicha comunidad podría situarse en Mesopotamia o Persia.

b. En segundo lugar, el padre de la viuda se convertía en reo de muerte si no respetaba el orden de levires. La pena de muerte no está estipulada en la Ley de Dt 25,5-10, aunque parece implícita en Gn 38, puesto que Judá no casó a su hijo con nadie, aunque no se decidía a entregarlo a Tamar. Se puede suponer que Judá no tenía derecho a entregar a Sela a otra persona que no fuera Tamar, y que, tal vez, si lo hiciera, sería reo de muerte. Sin embargo, en esa historia la decisión corría a cargo de Judá, el padre del siguiente levir, y no se habla del padre de Tamar. Tampoco en la historia de Rut se habla de su padre, que era, seguramente, moabita, ni del padre de Booz. También esta pena de muerte puede deberse a que la comunidad se estaba desintegrando, y a que había que tomar medidas drásticas para evitarlo. Esto, sin embargo, yendo más allá de lo que estipulaba la ley.

c. En tercer lugar, como ya dije, en Tobías, el levir en turno no estaba obligado a renunciar públicamente a su derecho-obligación, siendo que la ley así lo estipulaba. Si el varón tenía que hacer renuncia pública de su derecho-obligación, Tamar hubiera podido exigir a Sela que se casara con ella o que la dejara en libertad. En el caso de Rut, tal parece que ella pide a Booz que cumpla con la ley o que renuncie públicamente, pero Booz no era el pariente más cercano, por lo que tuvo que exigir a dicho pariente que renunciara públicamente. Seguramente, si él tampoco hubiera querido cumplir, también habría tenido que renunciar públicamente. El caso de Sara es diferente. Ni su padre ni ella querían exigir a Tobías que cumpliera, más bien, al contrario, no querían ni que se hiciera presente para reclamar su derecho, ni que renunciara públicamente a él, pues Sara no tenía interés en otro matrimonio con ninguna persona.

Ningún libro bíblico de la época (a no ser que Rut haya sido escrito en esos años), habla de la ley del levirato, sin duda vigente, pues los saduceos plantearon a Jesús un caso similar al de Sara y Tobías (cf. Mt 22,23-33; Lc 20,27-40).

El tema del levirato es poco tratado en otros libros de la época. En el Libro de los Jubileos, no es Judá quien da largas al asunto del matrimonio de Sela con Tamar (cf. Gn 38,11), sino la esposa de Judá (cf. 41,6); mostrando así una autoridad contradictoria con lo que señala el libro de Tobías. El Testamento de los doce patriarcas no habla del 
levirato sino de manera tangencial, en Jud 3,4-8, explicando el sentido de quitar la sandalia al que no da descendencia a su hermano difunto.

Así, pues, Tobías se separa de los demás libros bíblicos y apócrifos, por cuanto tiene un interés especial en el levirato, aunque con matices que lo alejan de Palestina y de la diáspora cercana.

\subsection{La mujer en la familia}

Es muy difícil saber cuál era la realidad de las familias en épocas del Antiguo Testamento, pues las narraciones hablan de personajes importantes, patriarcas, jefes de clan, jueces, reyes, etc., que podían, en la mayoría de los casos, tener varias esposas y concubinas.

a) Antes de la legislación deuteronómica, la poligamia era una práctica común. Después del Destierro, la práctica de la poligamia, aunque permitida, se limitaba a algunos personajes potentados.

En Tobías, las tres familias que se presentan son monogámicas, como he descrito más arriba. Los últimos libros bíblicos del Antiguo Testamento no hablan de casos de poligamia e incluso parecen dar por supuesta, en el pueblo común, la monogamia. ${ }^{76}$

En Libro de los Jubileos se asume la poligamia sin dificultades (cf. 14,21-24). Tal parece que lo mismo puede decirse de la Carta de Aristeas (cf. 250). El Testamento de los doce patriarcas habla muy poco de ella, exceptuando las menciones a las dos esposas de Jacob. En Is 1,10; 2,13 se reporta una discusión entre Raquel y Lía por el control que podían tener sobre Jacob. El libro parece tener como ideal de matrimonio la monogamia: Rub 4,1; 6,2; Lev 9,10;11,1; 12,4; Jud 8,2; Is 5,3; 6,2; 7,2; Jos 10,2.3.

Entre los documentos de Qumrán, en el Documento de Damasco 4,20-5,2, y en los Fragmentos de una obra sadoquita (cf. 7,1.5) se manda que no haya poligamia, ${ }^{77}$ que tampoco era aceptada en el imperio romano.

${ }^{76}$ Cf. Sir 9,2; 23,18; 25,8.16-18; 40,23; Qo 9,9. Aunque Sir 37,11 supone que todavía había poligamia.

77 Entre los escritos del Mar Muerto, fue encontrado un archivo personal de una mujer que vivió en la primera mitad del segundo siglo d.C. Se refieren a una mujer llamada Babatha, que fue la segunda esposa (viviendo aún la primera), de un hombre llamado Judá. Esto confirma que la poligamia era más o menos común entre los judíos de la época. Según esos archivos, Judá da a su hija la mitad de sus bienes al casarse, y le promete la otra mitad como herencia. Tal como hizo Ragüel con Sara. 
b) En cuanto al adulterio, y la prostitución, Tobías no dice nada fuera de la confesión de Sara, respecto a que está libre de todo contacto de varón y que no ha mancillado su nombre (cf. Tb 3,15), ni siquiera en comparación con la idolatría. Tal vez la comunidad a la que estaba destinado el libro no tenía el problema de la atracción de otras religiones o veía como tema urgente la endogamia.

En el Libro de los Jubileos se dice que el diluvio fue desatado por la fornicación y la impureza (cf. 7,20), mientras que el Génesis no pone ningún acento en lo sexual (cf. Gn 6,5). Lo mismo dice el Libro de Henoc $^{78}$ (cf. 1 Henoc) con insistencia: 6-11. Por lo que no había perdón para los ángeles que eso hicieron (cf. 12.19, etc.), pues, siendo inmortales, y no necesitando mujeres, se metieron con ellas (cf. 15,1-5.7). Fuera de esas menciones, el libro no se ocupa de las mujeres.

El Testamento de los doce patriarcas se preocupa mucho del adulterio, la prostitución y los abusos de tipo sexual. Advierte frecuentemente contra el adulterio: Rub $1,7-9 ; 3,10-12$; 4,2-11; 5,5.6; 6,4; Sim 5,5; Lev 6,8.10; 9,9; 14,16; 15,1; 17,11; Jud 14,2-3; Ash 2,8; 4,3; Ben 7,$1 ; 10,10$; y sobre todo el testamento de José (por la exposición de las intrigas de la esposa de Putifar): Jos 2,1-2; 3,1-3.8; 4,2-6; 5,1; 6,1-8; $7,4.8 ; 8,2-5 ; 9,1-5 ; 14,1-5 ; 16,1.4$. Con menos frecuencia, pero también con insistencia, contra la fornicación -que a veces quiere decir adulterio y a veces prostitución-: Rub 3,1.3.15 (que Rubén violó a Bilhá estando ella dormida, cf. Gn 35,21-22); 6,1.4; Lev 2,3; 5,3; 6,3 (en general, las referencias sobre el tema que están en el testamento de Leví, se refieren a la violación de Dina por parte de Siquem, cf. Gn 34,1-5); 6, 8; 7,4; 14,56; Jud 12,2-3 (Judá se excusa de su relación con la prostituta Tamar, diciendo que estaba borracho); 12,8; 14,2-3; 18,2; 23,1; Is 4,4; Dan 5,5; Ash 2,8; Ben 7,1.

${ }^{78}$ Henoc es un compuesto de varios fragmentos. Fue escrito entre los siglos ॥ y I a.C., aunque contiene textos del s. III a.C. Cf. A. DíEZ MACHO, "Libro etiópico de Henoc (1 Henoc)", Apócrifos I, 231. F. Corriente - A. PIÑero, "Libro 1 de Henoc", Apócrifos IV (ed. Díez Macho), 13-143, concluyen que 6-36 debieron haber sido escritos antes del 166 d.C., seguramente durante el siglo II a.C.; en cuanto a 37-71, habrían sido escritas entre la mitad del primer siglo a.C., y los finales del primer siglo d.C.; $72-82$ debe remontarse, según ellos, al siglo III a.C.; 83-90, antes del 160 a.C.; 91-105 tiene dos partes: el Libro de las enseñanzas y los castigos, que sería de la época de Alejandro Janeo (104-78 a.C.), y el Apocalipsis de las semanas, que debe ser anterior al 167 a.C.; los Fragmentos del libro de Noé serían del siglo III a.C. 
El Apocalipsis sirio de Baruc (2 Baruc) ${ }^{79}$ casi no tiene mención de mujeres. Sólo las recuerda tratándose del castigo de los ángeles que se unieron a ellas (cf. 2 Baruc 56,12-13), de los pecados que cometió Manasés con algunas de ellas (cf. 2 Baruc 64,2), y de los sufrimientos que se aproximarían, cuando mujeres llegarían al extremo de comer a sus hijos (cf. 2 Baruc 62,4). En la misma línea, los Salmos de Salomón hablan muy poco de la mujer, y cuando lo hacen, quieren deplorar los pecados que se cometen con ella: prostitución (cf. 2,$13 ; 4,4.5$ ), adulterio (cf. 4,6.15; 8,11; 16,7.8). Reprueba también el incesto (cf. 8,10).

El Pirke Abot dice que una de las causas del Exilio fue el incesto (cf. 5,11) ${ }^{80}$ En los Fragmentos de una obra sadoquita se advierte en contra de la fornicación (cf. 6,11), y de ir con prostitutas (cf. 8,18). El pecado de fornicación de David contaminó al santuario (cf. 7,8-9). Los dichos del Pseudo-Focílides ${ }^{81}$ aconsejan no tener relaciones sexuales vergonzosas, no traspasar los límites de la sexualidad natural y que la mujer no tome el rol del varón.

c) El divorcio era aceptado por la ley ${ }^{82}$ y estaba arraigado en la sociedad. ${ }^{83}$ Sin embargo, también el divorcio empezó a ser desaconsejado después del destierro. ${ }^{84}$ Tobías no habla de él, y tampoco es un tema que haya preocupado a los autores de los tres últimos siglos antes de Cristo. Se menciona muy poco y prácticamente sólo para prohibirlo, como en los Fragmentos de una obra sadoquita (cf. 7,1.5) y en los documentos del Mar Muerto (11QTemplo 55,16-19). En el imperio romano, el divorcio era relativamente frecuente.

79 El Apocalipsis sirio de Baruc, o 2 Baruc, fue escrito por personas afines al fariseísmo, entre los años 50 y 90 d.C., cf. R. ChARLES, "2 Baruch, or The Syriac Apocalypse of Baruch", Apocrypha II (ed. Charles), 470-526. A. Díez MACHo, "Apocalipsis siríaco de Baruc", Apócrifos I, 284, opina que fue escrito entre el 80 y el 130 d.C.

${ }^{80}$ El capítulo 5 fue, según Herford, "Pirke", Apocrypha II (ed. Charles), 686-714, añadido por R. Judah.

81 Según Coluins, "Marriage". El Pseudo-Focílides fue escrito, según el mismo autor, en torno al cambio de era.

${ }^{82}$ Cf. Dt 24,1-4.

${ }^{83}$ Cf. Ex 18,2; 1 Sam 18,27; 25,44; 2 Sam 3,14-16; Esd 10,10-14; Sir 25,26.

${ }^{84} \mathrm{Cf} . \mathrm{Ml} 2,14-16$. 
d) La endogamia se acentuó los últimos siglos de la era precristiana. ${ }^{85}$ Tobías se había casado con Ana, una mujer de su tribu (cf. Tb 1,9), y pidió a Tobías que hiciera lo mismo (cf. 4,12). Tampoco éste es un tema al que recurran los autores de los tres últimos siglos anteriores a Cristo.

La endogamia fue, sin duda, uno de los motivos por los que el autor de Tobías usó como modelos los relatos patriarcales. De esa manera alentaba en los desterrados la ilusión del regreso. Esa práctica se acentuó en el destierro y en Palestina, en las épocas de crisis. Sin embargo, la endogamia es relativizada en el mismo libro. Esto se ve en que no se la menciona en las órdenes finales de Rafael (cf. Tb 12,6-9), ni en las últimas instrucciones de Tobit a Tobías, así como tampoco en la visión de la nueva Jerusalén. Evidentemente, no era indispensable que se hablara de la endogamia en esos casos, pero su ausencia no deja de tener cierta importancia. ${ }^{86} \mathrm{Si}$ Rut fue escrito en esta época, sería un testimonio de que, dentro de la comunidad judía, algunos no estaban de acuerdo con el etnocentrismo.

En el Libro de los Jubileos se insiste en la endogamia. Para él, las genealogías válidas excluyen a los cainitas, además de que las mujeres juegan un rol importante en ellas. En 30,7-11 se establece que el israelita que dé una de sus hijas a un gentil, debe ser apedreado. En 27,7-88 se dice que Rebeca se había enemistado con Esaú, porque este se había casado con cananeas, y fue quien puso en guardia a Jacob en contra de la exogamia (cf. 22,20). También el Testamento de los doce patriarcas advierte contra la exogamia: Lev 14,6; Jud 13,6-8; 14,6; Ben 10,10.

En resumen, la situación de la mujer en el matrimonio estaba bastante generalizada. En cuanto a la poligamia, se seguía aceptando legalmente, pero parece que, en la práctica, no era aconsejada. El adulterio y la prostitución, eran ampliamente combatidos. Los apócrifos que hemos estudiado revelan que el tema de la fornicación era motivo de preocupación para los autores y las comunidades destinatarias. A pesar de $\mathrm{Tb} 3,15$, el tema no parece de gran trascendencia en Tobías. Tal vez la comunidad destinataria o de origen del libro era pequeña y en ella el

85 Incluso para los judíos de Palestina, como lo atestiguan los documentos de Qumrán y el Libro de los Jubileos, según D. Rothstein, "Sexual Union and Sexual Offenses in Jubilees", JSJ 35 (2004) 363-384.

86 Cf. D. MCCRACKEN, "Narration and Comedy in the Book of Tobit", JBL 114 (1995) 401-418. 
control de la mujer era absoluto. Por último, Tobías insiste notoriamente en la endogamia.

\section{Conclusión}

Primeramente hice una descripción de las familias que forman parte de la narrativa de Tobías. Lo más significativo de ellas es que eran monogámicas, nucleares en la práctica, e implicaban la fidelidad sexual de los cónyuges. Los varones tomaban las decisiones, y se insistía en la endogamia y en el amor filial.

En el segundo apartado analicé lo referente al amor y al sexo en las familias, destacando la situación desventajosa y de sumisión (comparada con la cultura occidental actual) en que vivía la mujer. Constaté, ante todo, que el libro no habla, prácticamente, de amor, y que la relación de Ana con Tobit pudo ser descrita como conflictiva debido a que Ana lo sostenía económicamente. Además, señalé que el matrimonio era establecido por motivos de parentesco, conveniencia o legales, pero no por amor mutuo. Hice una digresión para mostrar cómo la traducción que Jerónimo hizo del libro no hace justicia a la "naturalidad" con la que en él se toman las relaciones sexuales. Finalmente, constaté -como en el apartado anterior- que la narración tiene muy poca consideración con las mujeres. Esto se ve, por ejemplo, en el hecho de que Rafael no haya dicho a Sara que era acosada por un demonio, del cual Dios lo había enviado a librarla.

En la última parte revisé la literatura contemporánea, escrita en Egipto y Palestina, en lo que respecta a la relación de la mujer con Dios, con el varón, el levirato y las relaciones familiares. En cuanto a la relación de la mujer con Dios, Tobías desentona con el conjunto de los libros analizados, por lo que -concluyo- es prudente pensar que no fue escrito en Palestina o Egipto. En cuanto a la relación de la mujer con el varón, constato que la situación de eterna minoría de edad de la mujer era algo generalizado en el judaísmo y que Tobías no es la excepción aunque en él se acentúe más el tema de la endogamia. En el apartado dedicado al levirato, constaté que Tobías lo hace más estricto, yendo más allá de las normas legales. Esto podría ser un indicio de que fue escrito en un lugar alejado de Jerusalén y en una comunidad pequeña de la diáspora. En lo 
referente a las relaciones de la mujer en medio de la familia y la sociedad, constaté que los libros de la época ponían más cautelas en la pureza. Otro caso es el de la endogamia, y el control de la mujer, que para nuestro autor eran temas de preocupación. Esto también puede contribuir a situar la elaboración del libro en una comunidad pequeña de la diáspora mesopotámica o persa.

JAVIER QUEZADA DEL RÍO

MÉXICO

javier.quezada@uia.mx 